\title{
RANCANG BANGUN SISTEM APLIKASI KEUANGAN SISWA PADA SMP ISLAM AL-MUHAJIRIN DEPOK
}

\author{
Muhammad Ilham Idris Yunus ${ }^{1}$, Puput Irfansyah ${ }^{2}$, Wahyu Nur Cholifah ${ }^{3}$ \\ Program Studi Informatika, Universitas Indraprasta PGRI \\ iidrisyunus97@gmail.com¹, irfandot@gmail.com², wnurcholifah@gmail.com
}

Submitted August 22, 2019; Revised March 29, 2020; Accepted March 30, 2020

\begin{abstract}
Abstrak
Pada era globalisasi ini hampir semua bidang organisasi menuntut dengan adanya sebuah kecepatan dalam menyelesaikan suatu permasalahan. Informasi yang efisien, cepat dan akurat serta tepat waktu sangat dibutuhkan untuk meningkatkan produktifitas, efektifitas dan efisiensi suatu organisasi. SMP Islam Al-Muhajirin Depok ialah salah satu organisasi yang bergerak dalam bidang pendidikan yang belum memiliki aplikasi khusus yang mengelola sistem keuangan untuk pendataan, pembayaran dan pembuatan laporan keuangan siswa. Tujuan penelitian ini untuk merancang sebuah sistem aplikasi keuangan siswa dan laporan keuangan siswa dengan menggunakan bahasa pemrograman java dan metode research \& development untuk mengembangkan suatu aplikasi yang efektif khususnya pada sistem keuangan siswa. Hasil sistem yang dibangun dapat mempermudah dalam menjalankan sistem keuangan siswa, sehingga lebih mudah dalam pencarian data yang diperlukan dan dapat membantu kinerja petugas tata usaha untuk lebih efektif dan lebih efisien.
\end{abstract}

Kata Kunci : Rancang Bangun, Aplikasi keuangan siswa, Java, MySQL

\section{Abstract}

In this globalization era, almost all organizations in many fields demand a quick solution to a problem. Efficient, fast accurate and timely information is certainly needed to increase the productivity, effectiveness and efficiency of an organization. The Islamic Junior High School AlMuhajirin Depok is one of the organizations engaged in the field of education that has not yet had a special application that manages the financial system for data collection, payment and preparation of student financial reports. The purpose of this research is to design a student financial application system and student financial statements using the Java programming language and research \& development methods to develop an effective application, especially for a student financial system. The results of the created system can help the running of a student's financial system, easing the finding of the necessary data and making more effective and more efficient performance of administrative officer.

Keywords : Design, Student financial application, Java, MySQL

\section{PENDAHULUAN}

Pada era globalisasi ini semua bidang menuntut dengan adanya kecepatan dalam menyelesaikan suatu permasalahan. Informasi yang efisien, cepat dan akurat serta tepat waktu sangat dibutuhkan untuk meningkatkan produktifitas, efektifitas dan efisiensi suatu organisasi.

Dalam hal mengelola keuangan siswa sebuah lembaga pendidikan, penggunaan komputer sangat dibutuhkan karena komputer digunakan sebagai alat bantu untuk melakukan aktivitas misalnya : pengumpulan dan penyusunan data-data keuangan, pengolahan keuangan dan penyusunan hasil laporan keuangan. Dengan memanfaatkan teknologi komputer, memudahkan pelayanan keuangan siswa menggunakan sistem komputerisasi, siswa yang ingin mendapatkan informasi mengenai 
pembayaran siswa pada administrasi keuangan dapat diberikan pelayanan dengan cepat, akurat dan efisien.

Teknologi komputer saat ini sangatlah penting dan sangatlah diperhatikan terutama untuk kalangan pendidikan. SMP Islam Al-Muhajirin Depok merupakan salah satu organisasi yang bergerak di dunia pendidikan. Pada prinsipnya SMP Islam Al-Muhajirin Depok selalu berusaha untuk memberikan pelayanan yang terbaik sesuai dengan kebutuhan termasuk pelayanan dalam keuangan siswa. Dengan adanya kebutuhan bagi siswa yang semakin hari semakin bertambah dan belum terpenuhinya oleh sistem pelayanan yang ada pada saat ini, maka diperlukan sebuah pengembangan dan penyempurnaan terhadap sistem yang telah ada dengan memperbaiki dari kekurangannya.

Mengingat semakin meningkatnya jumlah siswa dan siswi di SMP Islam AlMuhajirin Depok dan semakin rumitnya sistem pada Bagian Tata Usaha, serta untuk menghindari kesalahan dalam mengkalkulasikan data tersebut, maka SMP Islam Al-Muhajirin Depok telah melakukan pengolahan datanya secara terkomputerisasi tetapi belum maksimal, yaitu SMP Islam Al-Muhajirin Depok belum memiliki aplikasi khusus untuk mengelola sistem keuangan siswa, seperti: pendataan siswa, pembayaran iuran masih menggunakan aplikasi Microsoft Excel dan untuk pembuatan laporan pembayaran iuran kepada Kepala Sekolah Maupun Yayasan masih menggunakan cara yang manual sehingga memakan waktu yang lama dan sering sekali terjadi kesalahan dalam mengkalkulasikan data-data yang ada untuk proses pembuatan laporan.

Aplikasi adalah suatu subkelas perangkat lunak komputer yang memanfaatkan kemampuan komputer secara langsung untuk melakukan suatu tugas yang diinginkan oleh pengguna [1]. MySQL (My Structured Query Language) adalah penyimpanan data yang fleksibel dan cepat aksesnya sangat dibutuhkan dalam sebuah website yang interaktif dan dinamis [2]. Netbeans merupakan sebuah aplikasi Integrated Development Environtment (IDE) yang berbasiskan java dari Sun Microsystem yang berjalan diatas swing dan banyak digunakan sekarang sebagai editor untuk berbagai bahasa pemrograman [3].

Tujuan dari penelitian ini untuk mempermudah SMP Islam Al-Muhajirin Depok khususnya pada Bagian Tata Usaha yang mengatur keuangan siswa. Tujuan yang akan di capai yaitu untuk mengetahui perancangan sebuah sistem keuangan siswa yang sedang berjalan saat ini pada SMP Islam Al-Muhajirin Depok, mengetahui perancangan sebuah sistem aplikasi keuangan siswa yang akan dibuat untuk SMP Islam Al-Muhajirin Depok dan membuat sebuah sistem aplikasi keuangan siswa yang mudah dimengerti oleh pengguna dan dapat mempermudah proses pendataan siswa, pembayaran dan pembuatan laporan.

Manfaat dari penelitian ini adalah Diharapkan dapat membantu pihak sekolah dalam mengelola keuangan siswa agar tercapainya sistem keuangan siswa yang efektif dan efisien.

\section{METODE PENELITIAN}

Penulis menggunakan metode penelitian Research and Development yaitu adalah suatu proses pengembangan perangkat pendidikan yang dilakukan melalui serangkaian riset yang menggunakan berbagai metode dalam suatu siklus yang melewati berbagai tahapan [4].

Tempat penelitian yang dilakukan pada SMP Islam Al-Muhajirin Depok yang beralamat di Jl. Nusantara Raya No. 313, Depok Jaya, Pancoran Mas, Kota Depok, Jawa Barat 16432. 


\section{Metode Pengembangan Sistem}

Model waterfall dapat disebut juga sebagai model siklus hidup klasik. Model ini memungkinkan pemecahan misi pengembangan yang rumit menjadi beberapa langkah yang logis (desain, kode, pengujian, dan seterusnya) dengan beberapa langkah yang pada akhirnya menjadi produk akhir yang siap pakai [5].

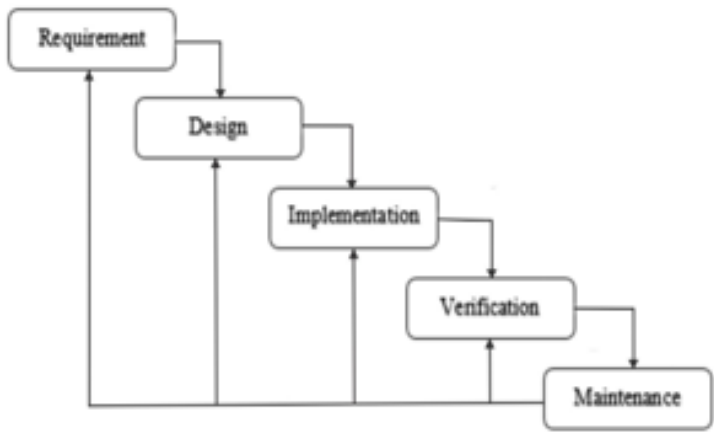

Gambar 1. Model Waterfall Sumber : [6]

Tahapan penelitian dalam pembuatan program disajikan sebagai berikut:

a. Studi literatur dengan mengumpulkan referensi yang dibutuhkan untuk membangun sebuah sistem dari berbagai sumber.

b. Metode Observasi dengan melihat dan menghimpun data-data yang dibutuhkan terkait permasalahan yang dihadapi.

c. Analisa dan perancangan terhadap sistem yang akan dibangun, seperti desain sistem, aturan sistem, pengolahan data, dan laporan.

d. Tahapan ini yaitu pembuatan aplikasi dilakukan yang kemudian akan diimpelementasikan, sehingga menjadi sebuah sistem dengan dasar bantuan literatur yang sudah di kumpulkan pada tahapan sebelumnya.

e. Ujicoba merupakan sangat penting karena pada tahap ini aplikasi di jalankan dan dilihat apakah ada yang kurang ataupun salah, dan tidak sesuai konsep yang dilakukan.

\section{HASIL DAN PEMBAHASAN}

Data Flow Diagram adalah representasi grafik yang menggambarkan aliran infromasi dan transformasi yang diaplikasikan sebagai data yang mengalir dari masukan dan keluaran [7].

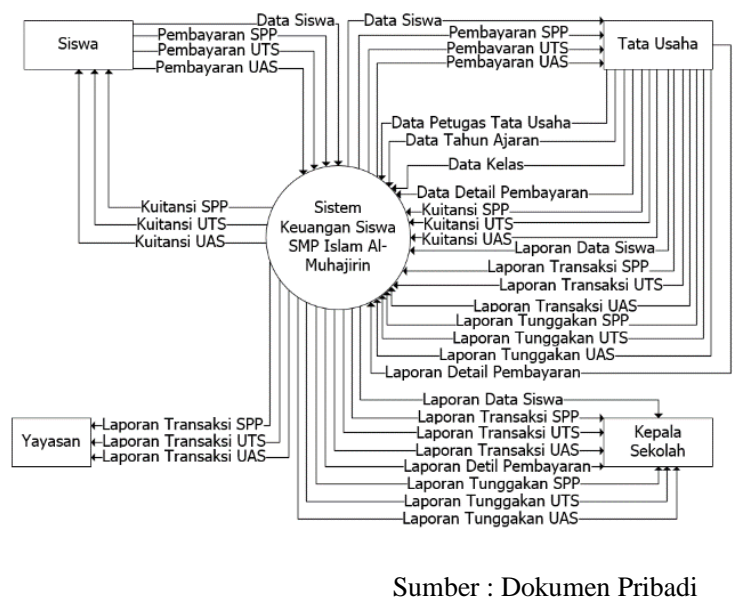

Gambar 2. DFD Konteks



Sumber : Dokumen Pribadi

\section{Gambar 3. Diagram Nol}

Normalisasi merupakan sebuah proses untuk mengelompokkan elemen-elemen data menjadi table-tabel yang menunjukkan entitas dari masing-masing relasinya [8]. 


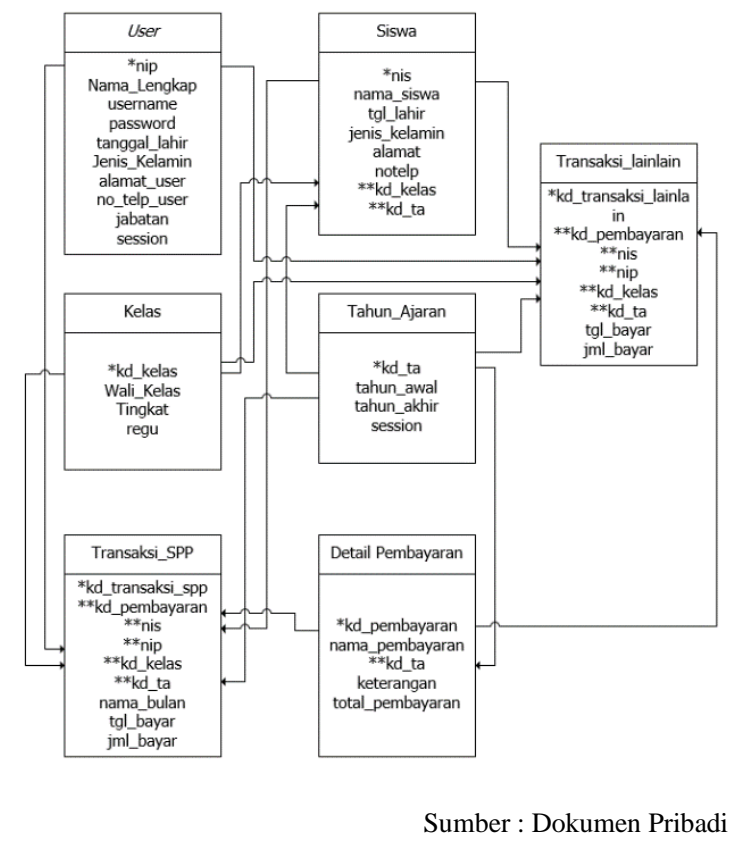

Gambar 4. Normalisasi

Tampilan layar antarmuka pada aplikasi keuangan siswa seperti dibawah ini :

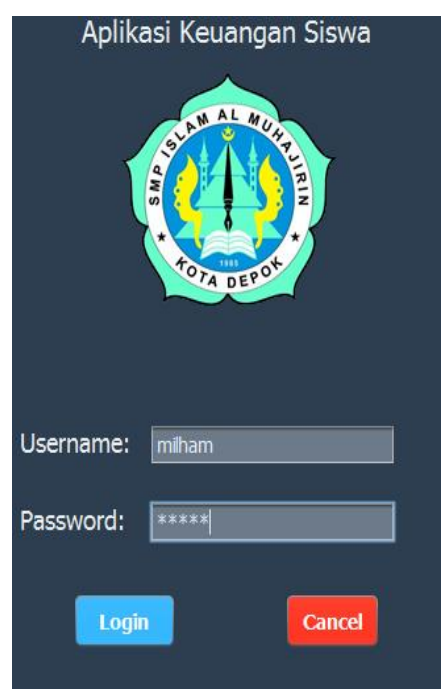

Sumber : Dokumen Pribadi

\section{Gambar 5. Tampilan Login}

Pada form login ini kita diharuskan untuk memasukkan username dan password agar dapat masuk ke aplikasi.

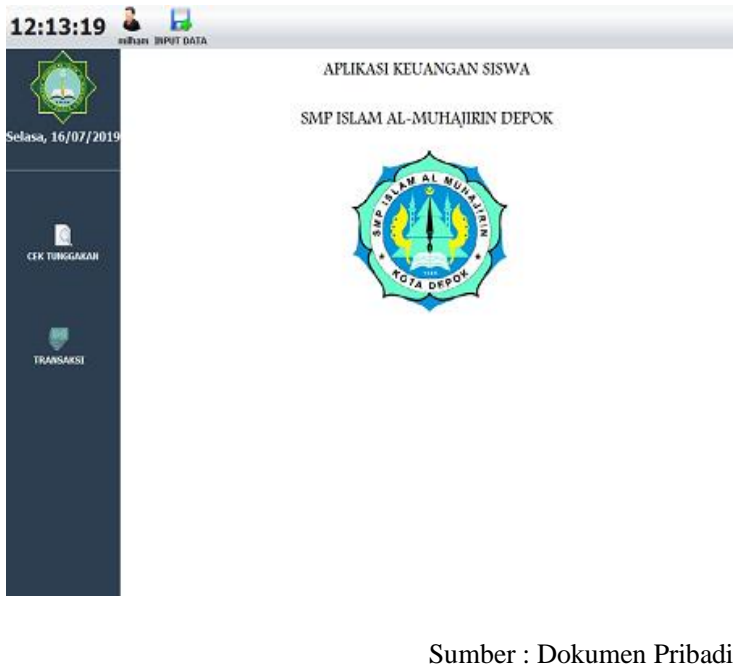

Gambar 6. Tampilan Menu Utama

Layar diatas menampilkan tampilan menu utama Aplikasi Keuangan Siswa SMP Islam Al-Muhajirin, pada menu utama tersedia pilihan profil, Input data, laporan, tabel, cek tunggakan, transaksi.

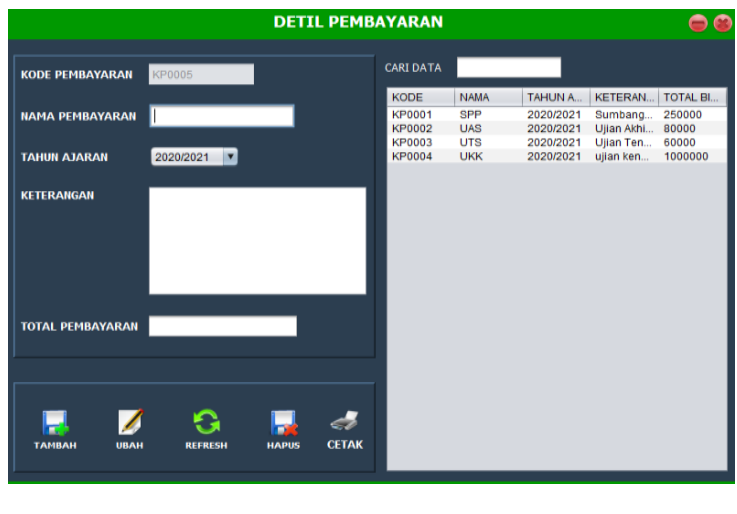

Sumber : Dokumen Pribadi, 2019

\section{Gambar 7. Tampilan Detail Pembayaran}

Pada form detail pembayaran ini user dapat menambahkan jenis pembayaran, mengubah jenis pembayaran, menghapus jenis pembayaran, jenis pembayaran ini akan digunakan untuk menentukan biaya pada proses transaksi pembayaran nantinya. 


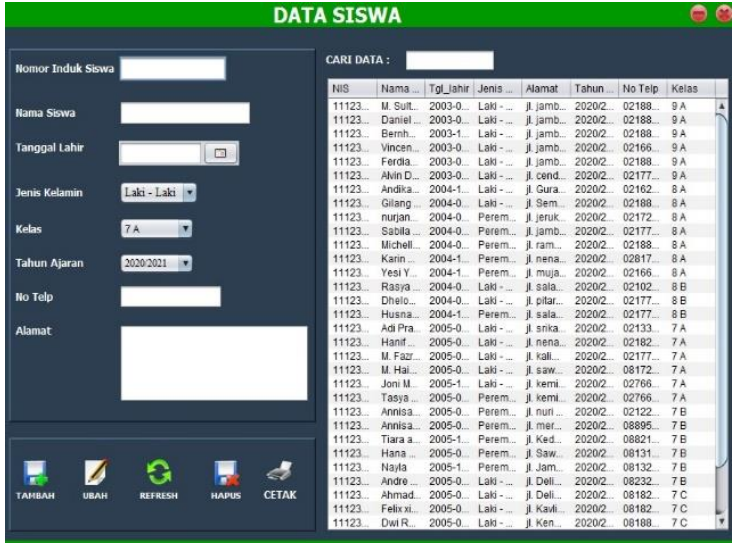

Sumber : Dokumen Pribadi,

\section{Gambar 8. Data Siswa}

Pada form ini user dapat melakukan penambahan data siswa, mengubah data siswa, menghapus data siswa ataupun mencetak keseluruhan data siswa dengan menggunakan tombol yang telah disediakan, tombol refresh digunakan untuk menyegarkan halaman form.

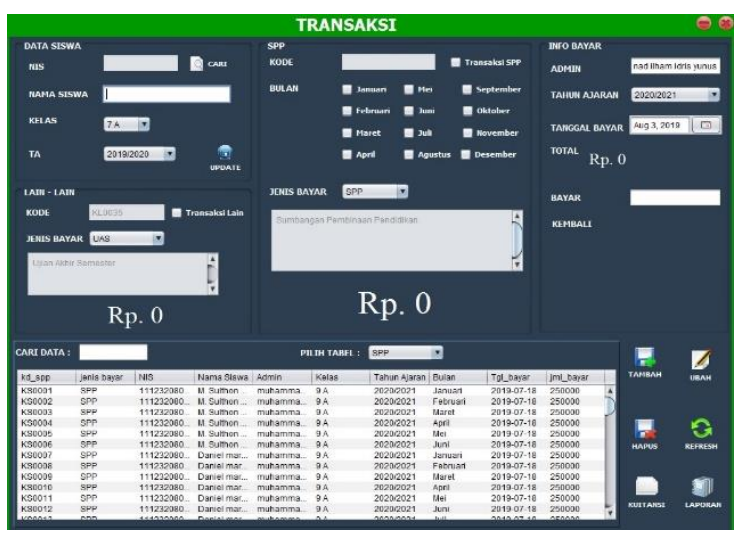

Sumber : Dokumen Pribadi

\section{Gambar 9. Transaksi}

Pada form ini user dapat menginput data transaksi pembayaran yang ingin dilakukan oleh siswa mulai dari menambahkan transaksi mengubah data transaksi, menghapus data transaksi lalu mencetak kuitansi dan laporan transaksi.

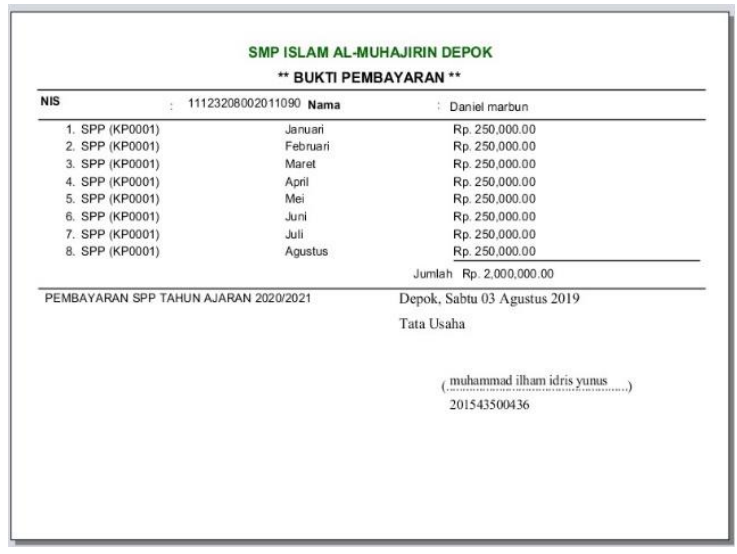

Sumber : Dokumen Pribadi

\section{Gambar 10. Kuitansi Pembayaran}

Ini adalah Kuitansi Pembayaran yang memberikan rincian biaya transaksi pembayaran yang telah dilakukan.

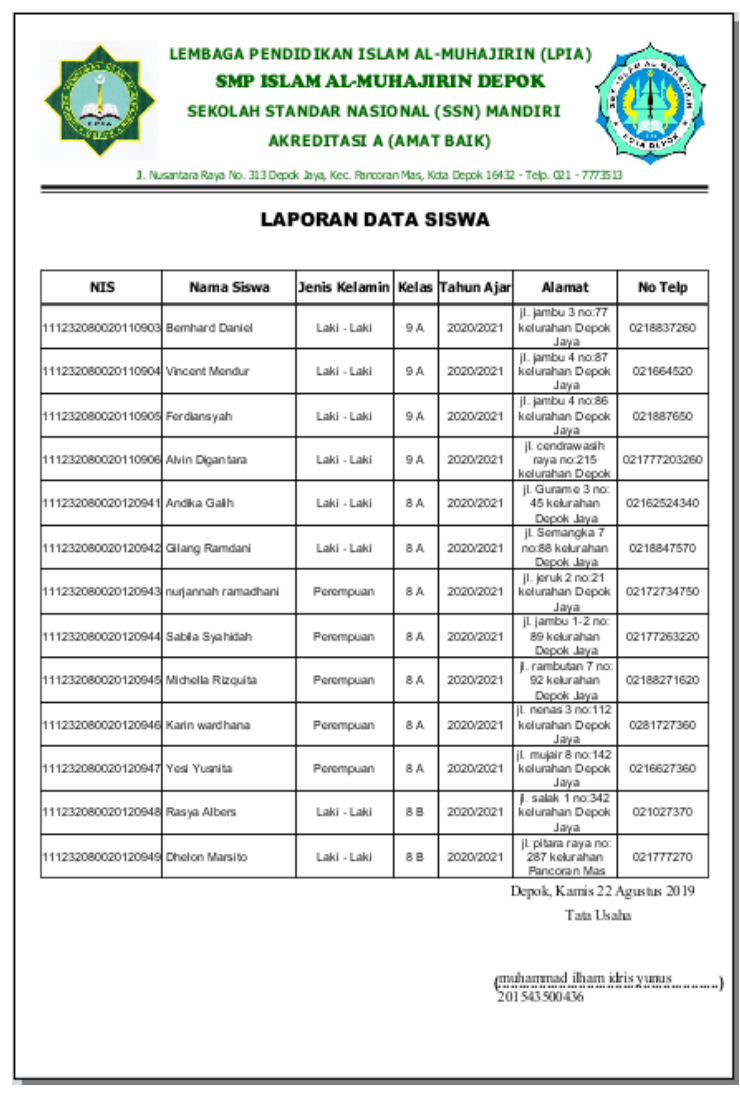

Sumber : Dokumen Pribad

\section{Gambar 11. Laporan Data Siswa}

Laporan ini memberikan informasi data siswa yang telah terdata pada aplikasi 
sistem keuangan siswa yang selanjutnya laporan ini akan diberikan kepada Kepala Sekolah sebagai arsip.

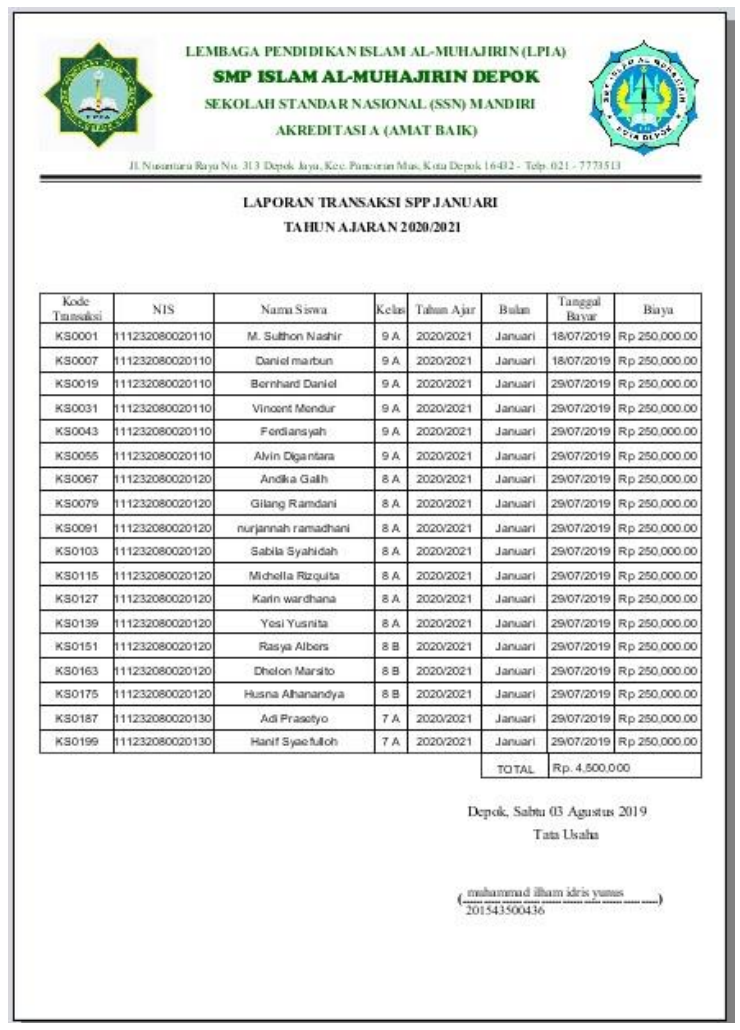

Sumber : Dokumen Pribadi

\section{Gambar 12. Laporan Transaksi SPP}

Laporan Ini memberikan informasi mengenai siswa yang telah melakukan pembayaran SPP pada setiap bulannya yang kemudian laporan ini akan diserahkan Bagian Tata Usaha kepada Kepala Sekolah dan Yayasan.

\section{SIMPULAN}

Berdasarkan hasil penelitian dan pembahasan mengenai rancang bangun sistem aplikasi keuangan siswa dapat diambil kesimpulan antara lain:

1. Dengan Rancang Bangun Sistem Aplikasi Keuangan Siswa maka mempermudah Bagian Tata Usaha dalam mengelola data keuangan di SMP Islam Al-Muhajirin Depok
2. Rancang Bangun Sistem Aplikasi Keuangan Siswa dapat meningkatkan pelayanan pembayaran bagi siswa di SMP Islam Al-Muhajirin Depok.

\section{DAFTAR PUSTAKA}

[1] N. Safaat, Pemrograman Aplikasi Mobile Smartphone dan Tablet PC berbasis Android. Bandung: Informatika, 2012.

[2] Madcoms, Kupas Tuntas Adobe Dreamweaver CS5 Dengan Pemrograman PHP \& MySQL. Yogyakarta: Andi, 2010.

[3] Nofriadi, Java Fundamental Dengan Netbeans 8.0.2. Yogyakarta: DeePublish.

[4] M. Ali dan M. Asrori, Metodologi dan Aplikasi Riset Pendidikan. Jakarta: Bumi Aksara, 2014.

[5] J. Simarmata, Rekayasa Perangkat Lunak. Yogyakarta: Andi Offset, 2010.

[6] R. Pressman, Rekayasa Perangkat Lunak (Pendekatan Praktisi) Edisi 7 Buku 1. Yogyakarta: Andi, 2012.

[7] R. Sukamto dan M. Shalahuddin, Rekayasa Perangkat Lunak Terstruktur dan Berorientasi Objek. Bandung: Informatika, 2014.

[8] Fathansyah, Basis Data. Bandung: Informatika, 2012. 